\title{
On Commercial Advertisement and Design Ethics
}

\author{
Junhong Gao \\ School of Art \\ Inner Mongolia University \\ Hohhot, China
}

\author{
Li Cao \\ School of Art \\ Inner Mongolia University \\ Hohhot, China
}

\begin{abstract}
The infinite design originality and the relatively finite natural resources is a pair of contradiction. This contradiction will be aggravated when the "people oriented" design philosophy has changed to "people's con.sumption oriented" in reality. Viewing commercial advertisement from the perspective of design ethics, we can find that the advertisement with the goal of sales promotion is unilateral and violates the path of sustainable development. The nature and final goal of commercial advertisement and design is not to stimulate consumption blindly, but to advocate green consumption concept and harmonious way of life. The benign ethical guidance of advertisement can create a healthy and harmonious ecological environment between advertisement design and commercial consumption. Only by this way can the long-term benefits of commercial design be reflected.
\end{abstract}

Keywords-design ethics; commercial advertisement; consumption; ecological

\section{INTRODUCTION}

"Advertising is a science belongs to the category of information dissemination, and art is only a means which shall serve the goal of advertising". [I] Commercial advertisement is the comprehensive carrier of art and science, therefore, commercial advertisement is located between science and art. Therefore, in order to achieve the expected purpose of advertising, advertisement design can use such artistic methods as exaggeration, metaphor and contrast to express the theme. And that results in the problem about what is the purpose of commercial advertisement design.

The meaning of advertising is to "publicize widely", and commercial advertisement is a propaganda form to directly or indirectly introduce commodity information or provide services through certain media. The Encyclopedia Britannica defines advertising as a way of information spreading through a variety of promotional tools, such as magazines, newspapers, television, radio, posters and direct mail, etc., and pass it on to the audiences or listeners it wants to attract, with its aim of selling goods and services. The success of commercial advertisement design is judged by sales volume as for the entrepreneurs; and as for the designer, the success of advertisement design lies in whether it is adopted by party A.

As early as the 1950s, Chinese scholar Mr. Ge Gongzhen has pointed out that advertising is the history of business development, namely the records of cultural progress. Human life is becoming more and more happy thanks to the invention of science, and advertising is of the functions of promoting life and guiding life. Advertising is not only a means for the business circles to promote sales of goods, but also undertakes the mission of culture promotion and mass education. 2 Even to this day, commercial advertisement is guiding people's life style and influencing person's ideas all the time while it achieves promotion goal.

\section{ERA OF MATERIAL - GOAL OF COMMERCIAL ADVERTISEMENT: TO STIMULATE CONSUMPTION}

In this era of extreme abundance material, the fact that commercial advertisement promotes sales volume has become the common ultimate goal pursued by advertisers and merchants. In order to obtain more economic benefits, enterprises will make the targeted consumers acknowledge a product or business through advertising, and such intangible acknowledgement will directly trigger their desire to buy, thus to promote enterprise's sales. In the process of advertising, the excellent advertisement must complete two tasks: one is that the product can bring the actual functional benefits to consumers, such as the portable function brought by Lenovo notebook's characteristic of light and thin; the second is to set up brand image through advertising creativity and expression, so as to create value added products (or enterprises) by its uniqueness. This kind of intangible assets created by advertising often far more than the tangible assets of the product itself, such as Nike, Coca-Cola and Adidas attract consumers by the additional meaning of their brands. Companies and designers pay more attention to whether or not the image is attractive and stimulating with stunt. And a large number of sexually suggestive advertisements with a nature of eroticism make use of "sex" to attract consumers and leave them with profound impression. In order to cater to some vulgar taste, sexually suggestive ads have openly entered into our life.

However, the commercial value of advertisement design directly influences the aesthetic values and ethics of its art form. Under the temptation of "advertisements bring about tens of thousands of dollars", advertisement design shall describe the commodity's use value objectively and truly, and create a vivid artistic conception, to correctly guide life concept. The core of design ethics is to guide reasonable and moderate consumption and avoid excessive consumption. If the goal of advertising is only defined as promotion, this will not only be the tragedy of advertising circle, but also the sorrow of human development. 


\section{ERA OF RELATIONSHIP - SERIES OF SOCIAL AND ECOLOGICAL PROBLEMS BROUGHT BY EXCESSIVE CONSUMPTION AND CONSPICUOUS CONSUMPTION GUIDED BY COMMERCIAL ADVERTISEMENT}

In the era with backward economy and material scarcity, product function appeal is the primary target of commercial advertisement. In the modern consumption society, with the development of economy, products tend to be homogeneous, and attach more symbolic meaning to the products, namely the added value beyond products. The significance of taste, wealth, status and power, carried by the commodity as guided by modern commercial advertisement has become the content pursued by "conspicuous consumption". The possession of consumer goods is no longer taking their use value as purpose, but to take the added value of consumer goods as the main purpose of consuming behavior. The extreme publicity and guiding effect of commodity symbol value by advertisement makes people run after it. A lot of advertisements and brand promotion filled in image are developing constantly, shaping consumption desire, and the desire to be watched (strong desire to show identity and status). The unlimited expansion of such desire will certainly result in comparison and the pursuit of luxury lifestyle. The children who haven't graduated from school, even the students of primary school and kindergarten in most cities of China are vulnerable to the temptation of commercial advertisement, and they will compete to buy products with famous brand. So no matter adults or children will generally agree that they will be superior to others as long as they consume in such a symbolic world. Such inharmonious factor will be a strong seed buried in the children's mind, which is a kind of abnormal phenomenon of social development. The feeling to show off and make others envy is completely resulted by certain product or service.

Morris compared the modern city and the human society to a super tribe. In this super tribe, the human animals are the same as the captive animals in the zoo, in order to transfer their own defeatist sentiments resulted by competing the position of tribal leader, they will fabricate a variety of secondary pseudo tribes, and continue the game of competing the tribal leader of this pseudo tribe; the pursuit of fashion by modern human is just the high level imitation of the position mark representing high status by those who haven't reach the high status. But the changing fashion is made by the class who are in high status to differentiate from the lower people, and make them constantly follow3. Morris explained the reason why modern people pursue "fashion" crazily but never catch up with fashion, which results in that the consumers with low income prefer to wait for discount or price cut of products with famous brand and their disposed products in order to keep up with those with high income, and do not even glance at the products that are unfamous but cheap and fine. I think it is a common phenomenon of losing ourselves. According to reason, human instinctive reaction should be ourselves, but we treat "fashion" according to others. In the end, it is the added value brought by advertisements when they are designing and spreading brand image that make people lose themselves and follow blindly.

Excessive production and consumption, dizzying advertisement design and large number of visual symbols make us living in a rich or even surplus visual culture, but still can feel the shortage and missing of certain requirement. Today, visual culture has eliminated the gap between the elite culture and popular culture, making everyone to share. But we are not satisfied with this sharing as everyone is pursuing personality. And the personality display has a fashion of life, but in reality, we are surrounded by a mass of replica, and aesthetic practice and aesthetic idea tend to assimilation. Especially the aesthetic consumption model guided and indicated by advertisement doesn't make our personality publicized, but instead, make us more mediocrity and popularization"4. "We lost our own perspective, but to view the world through the eyes of others, and we have lost the subject's awareness of freedom, the aesthetic personality has also been digested subtly. Therefore, the aesthetic problems of current visual design force us to re-examine its aesthetic value, calling on to give more aesthetic care and ethical orientation to vision"5. Commercial advertisement shall be responsible to show the correct world outlook, values and outlook on life with healthy contents, beautiful and elegant art form, in order to enhance the moral level of the whole society and purify social morality 6 .

The current era is not so much a material era as an era of social relations with people as the center, and material (natural objects and artificial objects) as the link. The raw material of artificial objects is derived from natural objects, and relies on the wisdom of people and technology processing; human is dependent on the natural environment, but also related to the small society of artificial objects; the nature continuously delivers nutrients and energies to human and artificial objects, but what have human returned to nature? Human strive to search for raw materials from nature to invite and create various artificial objects, and they discard them after enjoying.

\section{HARMONIOUS ERA-THE UltimATE GOAL OF COMMERCIAL ADVERTISEMENT DESIGN IS TO ADVOCATE A HARMONIOUS WAY OF LIFE}

The natural treasure human depends on for existence is becoming a giant dump. So today, we should not overly focus on the pleasure brought by material era, but should pay more attention to whether or not the relationship era made up by human and material, human and human, as well as human and nature is harmonious. In this relationship link, emphasizing of the material consumption and human oriented is single-faceted and unrealistic. The raising of material consumption level is not representative of the improvement of living standards, but the harmony to the largest extend of human, society and nature is the most precious. The design concept of "people-oriented" has developed into the "anthropocentrism". Human have ignored the precondition of survival and the normal circulation of ecological system while satisfying their own needs. The final direction design is to create a reasonable way of living and lifestyle. From this point of view, the essence and target of advertisement design is a proposal of harmonious way of life rather than blindly stimulating consumption. The ethics of design is to create a healthy and harmonious ecological environment of vision.

The infinite design originality and the relatively finite natural resources is a pair of contradiction. This contradiction will be aggravated when the "people oriented" design 
philosophy has changed to "people's consumption oriented" in reality. Design has been involved in the construction of consumption culture through participation in building brand, and we take the added value of goods as the value of our existence. Hence, design values have the limitations of the times 7. "The ultimate goal of art design is to build a more reasonable way of life for human, which should be consistent with the maximized human ideal." (Mr Du Dakai said so on the ninth national art exhibition). The more reasonable way of human life should include cherish resources, moderate consumption, giving play to people's creativity and the increase of happiness.

In the late 1960s, Victor Papanek, an American design theorist who is influential in ecological design theory proposed that the biggest role of design is not to create business value, nor the competition in packaging and style, but an appropriate element in the process of social change. He also stressed that design should treat the usage problem of limited earth resources seriously, and serve the protection of global environment. Ecological design has been generally regarded as the fundamental principles guiding design and the development direction of future design, whose $3 R$ (Recycle/Reuse/Reduce) core principles have indicated a direction for the development of design, and bring the innovation for the designers in terms of concept. Harmony is a doctrine, and moderation can help to maintain the stability of things, therefore, art design must also follow the rules of harmony, adhere to the principle of moderate and harmonious. It will be the largest profit for art design to correctly guide and advocate moderate consumption as well as construct the organic and harmonious society when dealing with the interrelation between the design objects, human, environment and social factors.

From another side, the most distinctive feature of commercial advertisement is practical, aesthetic and ethical, whose relationship is progressive, reflecting the three realms of truth, beauty and goodness. The "goodness" of commercial ethical is not only the foundation of "truth" of practical and the "beauty" of aesthetic, but also the highest goal of the both. First of all, from the perspective of audience, commercial ads have the practical function of information spreading; from the perspective of entrepreneurs, commercial ads are of great economic value potential. Only the "truth" of the two-way practical function is guaranteed can the commercial advertisement be an enduring one. If the truth of information spreading is lost, the appearance of commercial advertisement will just be a virtual soul. Aesthetic of commercial advertisement brings people about the sensory, emotional cognition and experience, while the commercial advertisement design in today's market pays more attention to the surface aesthetic in terms of visual and auditory stimulation and temptation. Only under the premise of ethics' "goodness", can the practical's "truth" and aesthetics' "beauty" develop normally and flourish. Also only take the "goodness" of ethics as the highest goal and direction of the "truth" of practical and the "beauty" of aesthetic, can the commercial advertisements survive forever. As the foundation of "truth" and "beauty", "goodness" is the basic quality of commercial advertisement designers and the industry's basic moral and behavior standard; and as the highest goal of "truth" and "beauty", "goodness" is the ethics core for harmonious coexistence between human and nature.

One famous economist once said that the main problem of human is moral ethics but not economic problems. Advertisement design has the short-term goal of bringing economic value and the long-term goal of ethical educating, and in the end, advertisement design is a matter about grasping the ethical dimension8. Ethic disorder will appear when the advertising has exceeded a certain scale, and when consumption has exceeded the scale of desire, excessive consumption will appear. Seek balance between economic and ecological ethics, advocate the correct and harmonious ecological life concept and make the advertisement design in conformity with the ethical and moral culture spirit, only by this way, can the advertisement design be able to step on the harmonious way under the relations of human, nature and society.

\section{REFERENCES}

[1] Chen Peiai. Development of Chinese Advertising Theories in 20th Century [J]. Journal of Xiamen University(Arts \& Social Sciences), 1999, (4).

[2] Ge Gongzhen. History of China 's Newspapers [M]. Shanghai: Shanghai Joint Publishing Press, 1955.

[3] [UK]Morris. The Human Zoo [M]. Shanghai: Wenhui Press, 2002.

[4] Meng Jian. Image Era- Theoretical Explanation of Visual Culture Communication [M]. Shanghai: Fudan University Press, 2005.

[5] Lin Yufeng. Viewing Today's Ethical Issues of Visual Design from Image Spreading [J]. Press Circles, 2008, (1).

[6] Shi Zujun. On the Bottom-line Ethics of Chinese Commercial Advertisement [J]. Hunan Social Sciences, 2005, (3).

[7] Dai Fuping. On the Cultural Characteristics of Consumption Era [J] Decoration, 2004, (4).

[8] He Xiaoqing. Symbolic Consumption and Advertisement Ethics [J]. Social Science Journal of Hunan Normal University,2007,(1). 